\title{
Re-configuring Participatory Media for Citizen Elders in Urban Planning
}

\author{
Rachel Clarke ${ }^{1} \quad$ Clara Crivellaro $^{1}$ \\ ${ }^{1}$ Open Lab \\ Newcastle University, \\ Newcastle Upon Tyne, UK \\ \{rachel.clarke\} \{c.crivellaro\} \{p.c.wright\} \\ @newcastle.ac.uk
}

\author{
Danilo Di Mascio² \\ Peter Wright $^{1}$ \\ ${ }^{2}$ School of Architecture \& Built Environment \\ Northumbria University, \\ Newcastle Upon Tyne, UK \\ danilo.dimascio@northumbria.ac.uk
}

\begin{abstract}
We discuss an experimental pilot study collecting and sharing media to explore active citizen engagement with older adults in the city. Our purpose was to inquire into the potential role of audio-visual media collection and presentation to inform urban planning. We encouraged collective documentation of the associations older people have with place and reflected on shared experiences within the context of mobile and civic technologies. We report on different phases of the study, contributing insights on the potential role of digital media to raise awareness and sensitivities to alternative perspectives providing expression of people's values. We speculate on potential opportunities for media architecture to present and re-mix media and make placebased contentions palpable.
\end{abstract}

\section{CCS Concepts}

- Human-centred Computing • Human Computer Interaction - HCI Design and Evaluation Methods • Field Studies

\section{Keywords}

Citizens, data, urban computing, walking, participation, older adults, place-making, urban planning, media architecture.

\section{INTRODUCTION}

As a nascent research field, media architecture has made significant steps in elaborating on the design and use of commercial, entertainment and arts-based experimental work within the built environment. The aesthetics of place, sensorial spaces that offer enchanting, enriching and playful experiences have been designed and evaluated in how media architecture can open up alternative ways for people to engage with urban environments [4][26][27]. More recent developments have seen a turn to more participatory, political and infrastructural concerns within cities [7][8][12][17], particularly in light of smart city development and the interconnected potential of mobile technologies and crowd-sourced data collection, presentation and action. Yet research in this area has so far paid little attention to the politics of place and concerns for who is included and excluded from the discourses and management of place-based media interactions for urban planning and development [18].

This work is licensed under a Creative Commons Attribution International 4.0 License.

Copyright is held by the owner/author(s).

$M A B^{\prime} 16$, June 01-04, 2016, Sydney, Australia

ACM 978-1-4503-4749-5/16/06.

http://dx.doi.org/10.1145/2946803.2946815
Drawing from mobilities research within the social sciences, [9][10][14][16] we report on an experimental series of design workshops with older adults. Our research questions focused on how to develop participatory practices for audio-visual media and data collection that were inclusive of diversity and that brought together different perspectives and forms of situated knowledge associated with place. In this sense our approach focused on bringing together sometimes conflictual points of view, while considering the importance of translation and communication between different expertise across multiple digital platforms.

We use our case study example to speculate on the potential role media architecture could play in making palpable different perspectives and contentious urban issues. Focusing on the redevelopment of major transport infrastructure routes through the city of Newcastle Upon Tyne in the UK, we provide an in-depth description of our process, including site visits, meetings, and workshops. These helped sensitize us to some of the concerns expressed by older adults in their feelings of not being listened to when proposing ideas to city officials. Our role as researchers was to provide alternative perspectives and further scope out future potential on how older adults might build capacity with other communities and to reflect on the role of media and data, its presentation and how it might be used in the context of citizen engagement in urban planning and design.

\section{OUR CONCEPTUAL ORIENTATION}

Mobile phones and off the shelf mobile technologies are increasingly used in many people's day-to-day lives for geotagged audio-visual documentation, as personal tracking devices to map and chart routes and to connect with people on the move. Many applications are therefore increasingly considered important for understanding people's movements within cities, not only for personal use, but for economic development and for city infrastructure and planning.

For instance commercial cycling apps such as Strava $^{1}$ make available aggregated data on popular routes within cities globally and sell detailed information to city councils to encourage evidence based decision making for improving cycle lanes. More explicitly civic oriented applications such as Street Bump encourage drivers to collect specific data about the quality of the roads within their area. The data is shared and analysed to provide real-time information for governments to make informed decisions about resources ${ }^{2}$. In the context of research bespoke mobile applications have been developed to directly connect

\footnotetext{
${ }^{1}$ https://www.strava.com/

${ }^{2} \mathrm{http}: / /$ www.streetbump.org/
} 
communities of interest with one another [5] and with local authorities. This has served to both connect people seeking to find specific services and to provide evidence for making significant changes to infrastructure. With both examples the contingent nature of data is highlighted as it is used to communicate between many different actors for many different purposes in supporting change [20].

Critical voices have, however, expressed concerns over surveillance and privacy perceived to be inherent in collecting and sharing data with mobile technologies, particularly in the context of future visions of smart cities and big data that are increasingly becoming an integral part of inner city infrastructure and planning [15]. Such visions can be suggestive of the regulatory logic of databases and spreadsheets used to categorise, manage and control [10]. Furthermore the same technology can be used to envision a politics of place, excluding very specific and more complex experiences, such as personal and emotional identifications with place, subtleties of tacit routines and social interactions [22]. Documenting movement and journeys using technologies can also perpetuate inequalities associated with class, age, gender, ethnicity and capacity [9][14]. Indeed such critical perspectives have informed the development of more bespoke responses in re-conceptualising the role of data as situated within place. This has gained further traction in communicating issues and concerns for local planning [25] and budgeting [12] where more deliberative and discursive forms of place-based data sharing have been explored for positive change.

As many of our urban populations both expand and age, looking towards experiences of the city from the perspective of older adults is increasingly important, yet often omitted [23]. While technology-based design has been mindful of such exclusions, research for older adults and mobility has often restricted its view to issues of accessibility for the reduced physical and cognitive capacity of individuals [21] [28], rather than focusing on more enriching perspectives such as well-being. While accessibility and well-being research can be of value, and in an attempt to be sensitive to social and emotional capabilities connected with place, our intention with this design-oriented inquiry was to draw from an alternative set of discourses within mobilities research. We focused on the interconnected relationships of people and things within the environment [10][14] the 'fragile entanglement of physical movement, representations and practices' [9][p159], explored through time. In this sense our design sensibilities were attuned towards working with digital media to be sensitive to historical connections, rhythms, experiences, frictions and stasis associated with transition and identities in place.

\section{SENSITISING TO PLACE}

Our design team is made up of interdisciplinary researchers working across architecture, anthropology, socially engaged arts and HCI. We are working together investigating how technology can support documentation and re-envisioning of the age-friendly city of the future. We positioned ourselves as design researchers bringing critical perspectives on how changes within future cities might be configured to be inclusive and equitable for those often excluded from discussions on inner city development. We adopted an action research approach working with cycles of collective reflection and action that fed into each phase. We began by meeting with the Elders' Council who were already in conversation with local authorities about inner city infrastructure and experiences of older adults. We worked with them to evaluate the City Walks [11] approach in relation to a 'live' inner city development and re-envision alternative media technologies and practices for the future.

\subsection{Place-based meetings, sharing concerns}

Over the last 13 years the Elders Council have regularly conducted physical assessments of the built environment through paper-based surveys with their 2000+ membership. Every assessment was analysed by a small team and presented back to the council in a yearly printed report. When initially meeting with us they expressed concerns that they felt they were no longer being listened to by the local authorities. They wanted to find alternative ways to engage wider publics in collecting evidence about their experiences of the built environment. At the same time some were also interested in the emotional associations with place and wanted to discuss their concerns with other groups in the region and communicate their experiences more widely.

In trying to gain a better understanding of the more technical interests of members, we attended sessions at their weekly Computer Club and invited a small group of members to a workshop within the university. We showcased a number of existing projects across digital and material design that researchers were already working on (Figure 1.). This included a range of systems associated with place-based research, including location-based mobile phone apps, 3D printing physical traces and movement, push button voting systems and audio maps. We asked members to discuss with us some of the opportunities and challenges that they felt these kinds of technology presented for them individually but also for their wider members.
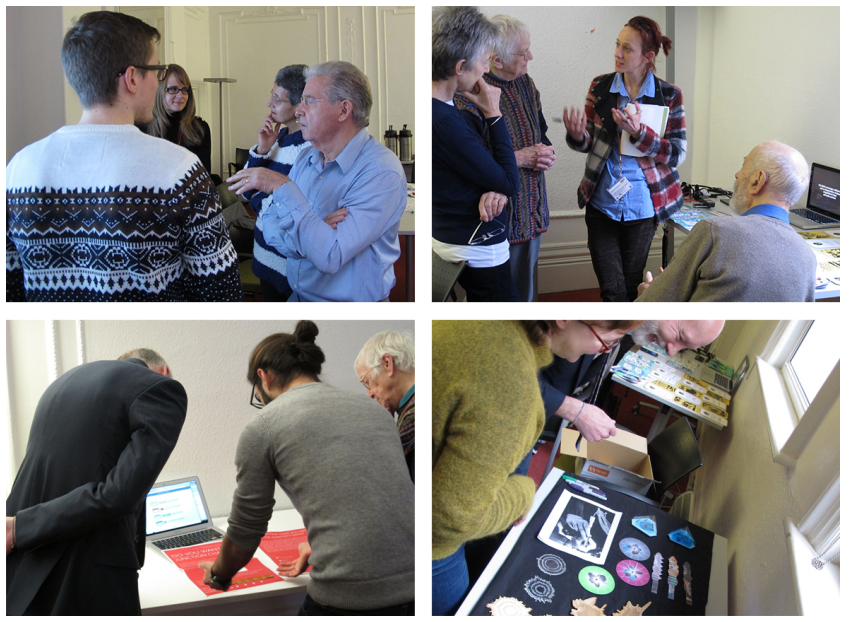

Figure 1. Elders' Council try out example technologies.

Individuals highlighted an interest in both physical and location based interaction with technology in the built environment. They felt this was important for discussing and connecting with people who may not have access to smartphones or the internet at home. Furthermore some wanted to find ways of using technology to increase and improve their social connections, while others wanted to find ways for technology to highlight their decreased capacities, such as reduced movement, hearing and vision, and the challenges this presented when moving around the city. The group showed significant interest in the City Walks approach and we made plans to organize this in relation to a specific area of the city.

\subsection{Plans for re-development}

As with many British cities, Newcastle Upon Tyne is currently undergoing significant changes in transport infrastructure associated with cycling and walkways. We attended several 
meetings with engineers, transport managers and community engagement officers who explained some of the plans and how they anticipated such changes would begin to take place. One of those meetings took place with the Elders' Council where officers presented a vision for the city for the next 20 years and the phasing in of such changes. Members of the Elders' Council expressed an interest in getting involved in feeding back insights and discussing ideas. Community engagement officers pinpointed John Dobson Street, a main traffic route through the city, as one of the first areas targeted for development (Figure 2).
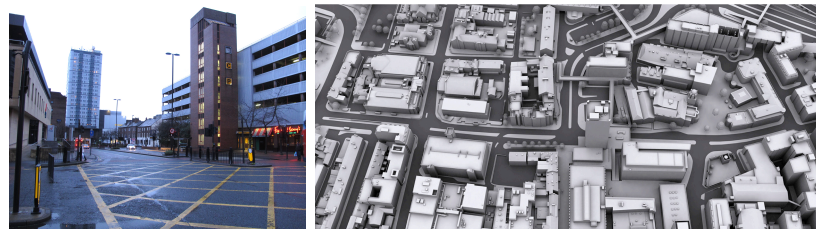

Figure 2. John Dobson Street in January 2015 and Virtual Newcastle Gateshead (VNG) 3D model reconstruction aerial view of John Dobson Street, used by the city council to create animated visuals of a journey along the street.

\subsection{Delving into the archives}

In discussion with members of the Elders' Council we planned a series of workshops that would initially encourage them to physically and digitally map their experiences of the street and present this back to the transport team at the city council. This would then be followed by a reflection on the effectiveness of such communication in making change while further envisioning alternative forms of communication for the future.

As researchers we began by gaining more historical perspectives on the road itself by searching in local archives and with local historical groups. This drew attention to the fact that the street had only been in place since the early 70 s and had been specifically designed to efficiently move cars between the new A1 motorway and the heart of the city directly connecting a newly built municipal building for councilors. In order to create the most efficient route for the road, many civic and cultural buildings had been demolished to make way for post-industrial modernization of Newcastle. This included separating pedestrians from cars, so that shopping and deliveries could be more easily organized, thereby in effect creating a highly capitalist vision of consumer values, rather than democratic or civic interests (Figure 3.).

The street was named after an influential northern architect, John Dobson who designed grand Georgian buildings within Newcastle in the $1800 \mathrm{~s}$. His most notable contribution to the city was his design of one of the first public railway stations in Europe. John Dobson Street, today is however, a congested through road dominated by cars, buses and car parks. In the archives, once the street was built, planners in the 80 s referred to it as 'nowhere street', its primary function to move traffic in and out of the city. It is a place specifically marked by transport infrastructure, with limited space for way finding and exploration [16].
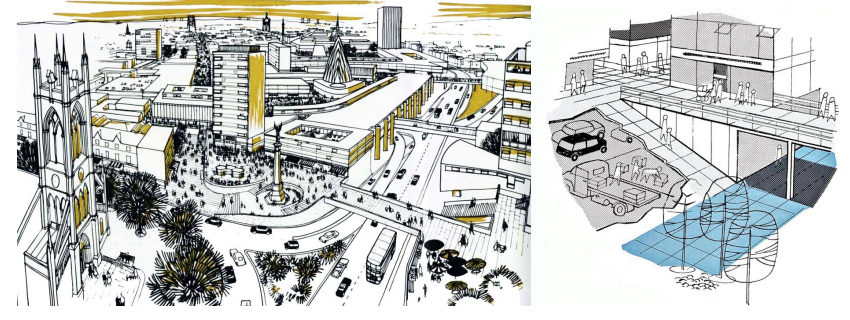

Figure 3. Newcastle city as envisioned in 1965 integrating infrastructure for cars and shopping.

\subsection{Learning through walking with}

Following our archive research we then brought the research team together to do a site visit by conducting a City Walk to reflect on how this approach might work in the context of the Elders' Council experiences and concerns. The City Walks approach includes a self-guided walk focusing on a fictional map drawn from historical references. We used the map to guide ourselves around the city. Along the way there were NFC tags attached to buildings that using a mobile phone triggered audio content from the archive about specific buildings or streets. We then added our own comments by recording a message that could then be accessed via the NFC for future walkers ([11] for more detail). The purpose of this was both to reflect on some of the archive material in situ, to see and feel some of the material consequences and how this had changed over time. However the walk also aimed at promoting discussion within our team about the different ways in which we, and others could understand a sense of place across time from different perspectives. While being in place and moving through it with our bodies, we could imagine the changes that had taken place in the past as well as imagine and share ideas on the changes about to happen in the near future. In this way the walk also aimed at providing us with first hand experience and understanding of the feelings forged in processes of negotiating multiple and different perspectives. While we were mindful that we may all experience things differently, that there would be resonances and connections we could make between one another, we also sought the experience of doing a City Walk together as a way that would help us design a more reflexive experience with the Elders' Council.

In walking with others and attending to the different parts of the street, we could feel some of the political tensions that had played out in the past as described in the archives, the removal of civic buildings for community benefit, the carving up of space for political will and the care we had to take with one another when walking down the street, especially when cars were so prominent on the journey.

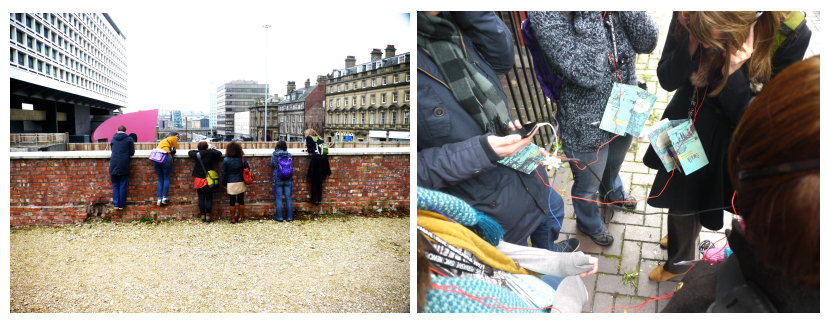

Figure 4. City Walks across John Dobson Street with our design team and listening to audio content from the archives.

\subsection{Developing a pilot tool-kit}

In consolidating our ideas from meetings, archives and our walk, we came together to work on adapting the City Walk as an approach to engaging the Elders' Council in walking and collecting data in alternative ways. With our respective interests in the politics of planning, sensory perception and poetics of architecture, we proposed a walk that could encourage bringing these perspectives together and developed a set of 6 prompt cards to reflect these perspectives. Each card consisted of an evocative image and a quote either from the archives or from our own experiences of being on the street. The cards were placed in one of 3 packs with a map of the street, pens, and a Zoom audio recorder and a digital camera. We chose these technologies in 
response to the desire of Elders' Council members to work with combined physical and digital artefacts. While some did have experience of smart phones, for this stage of the research we wanted to keep the technology as familiar and as easy to manage on the move as possible.

During this time we kept in close contact with the community engagement team at the city council, regularly updating them with short emails and phone calls. We requested more detailed information about the plans for the route prior to the workshop, but did not receive a response. However the day before the workshop the technical plans were released on a local news website. We downloaded and printed these, but the technical detail was difficult to interpret and so we decided not to include these in the final workshop.

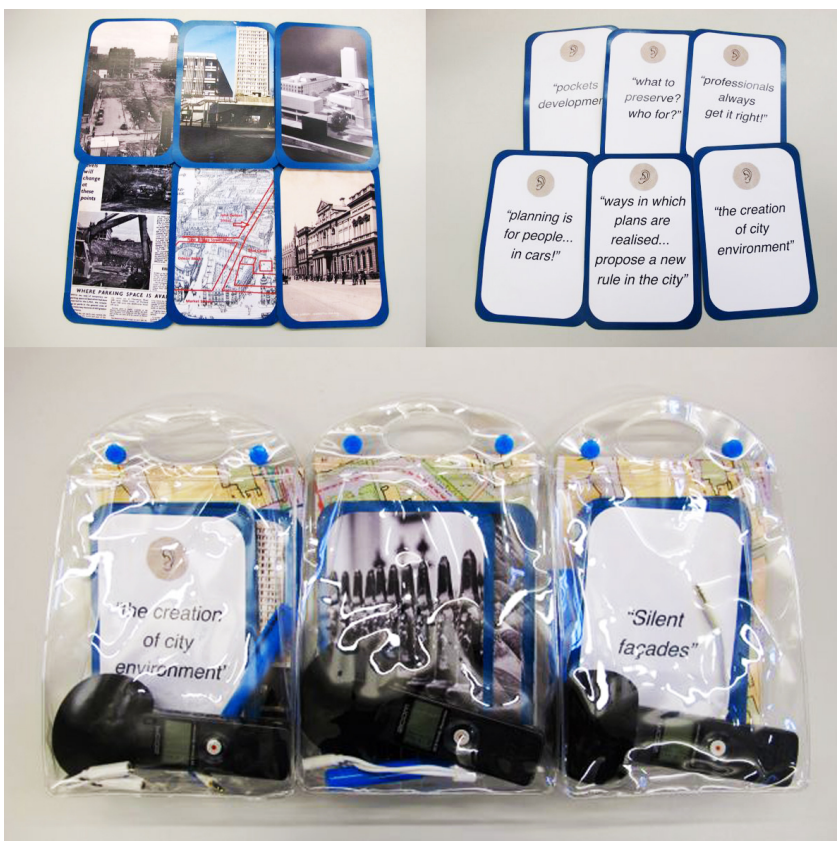

Figure 5. Packs for groups with audio-recorders, digital cameras, maps and prompt cards with images and quotes.

\section{CITY WALKS COLLECTING MEDIA}

7 members of the Elders' Council joined us for the workshop walk in February 2015. We audio-recorded the session and each of the group walks, while a photographer and our participants photographed parts of the journey. We began with teas and coffees and short introductions and reminders of who everyone was and their interests in attending. Some were part of the core group who managed regular walks for the Elders' Council to report on accessibility of walking routes within the city and wanted to develop new ways of engaging a wider team of people and making their voices heard. Others wanted to learn other techniques for working in groups collecting data about sensory impairment. Others were interested in learning more about cultural aspects of the city and how those could inform planning. In this first part of the workshop some also expressed considerable anger at the current proposals that had been released by the City Council the day before. This immediately highlighted the range and diversity of the group and some of the tensions such redevelopment prompted.

\subsection{Mapping journeys and perspectives}

To move discussion on we highlighted that our role as researchers was to experiment with alternative ways the group could use to collect data with and how they could present this within the context of urban development and planning. We asked the group to join us in a community mapping exercise aimed at drawing their regular journeys on John Dobson Street on a large map on the wall. We chose to do this as the first exercise of the day to open and facilitate shared discussion of local knowledge that constituted the group's everyday experiences of the street, to identify points of familiarity, resonance and highlight contentious issues[24]. Community mapping in this respect presents an opportunity to create more informal marks outlining people's recollections of movement through place, redrawing the more formal boundaries of buildings, roads and infrastructure and offers communities ways of reclaiming more formal cartographic principles.

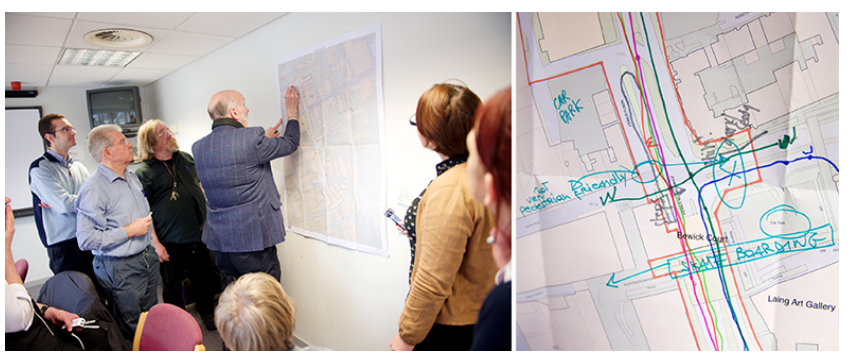

Figure 6. Community mapping exercise.

We explained that this exercise was a way of sharing the different ways the street was used and how individuals already felt about it, before we went for a walk. While some began to look at the map and work out where familiar landmarks were, others began to get frustrated at not knowing what the new proposals meant, calling for an explanation of the new proposals in order to meaningfully connect their mapping exercise to these wanted us to explain, otherwise they felt the exercise was pointless. We further highlighted how we too didn't understand the plans that had been posted online, so could not explain what they meant as we were not experts in the field of planning. We also stressed that the purpose of the workshop was to experiment with different forms of data collection, not currently practiced by the Elders' Council.

Participants initially began chatting about their different journeys and some described how they struggled to make sense of maps because of their aerial view. 'I never see the street in this way so it's hard you know, to know where we are in this.' Others agreed that this was one of the challenges with maps, and began helping each other to mark their journeys through and across the paper. Their initial reflections were functional in describing the different ways they were using John Dobson Street and the kinds of transport. However as the group began to mark their routes on the map, other comments began to highlight more aesthetic concerns; 'The street has no heart ... there's very little of interest on it, nothing to look at or to do, it just feels like a back street.'

Following the mapping exercise and discussion, over a hearty lunch we identified 3 areas and routes in, through and across John Dobson Street that the group felt presented particular tensions for their own experiences of the street.

\subsection{Out on the street}

After lunch the group split into 3 smaller groups, each taking a separate pack to focus on either the politics of planning, poetics or perceptions of place. We gave the group the following 
instructions: choosing 2 of the 6 cards they felt were most relevant; taking them to as many of the locations they had previously identified on the map and that they felt would resonate most with their chosen card; on arriving at the location, they were also instructed to take a photograph of one another the location and record a comment on the audio-recorders. Other members of the group were then invited to respond and record a further comment to this response.

The first group working with the politics of planning theme cards focused their efforts on areas they felt were dominated by car parks, which instead could be turned into family parks or used for cultural events. The second group used a FlipCam to record their walk and took continuous video footage along the way. This documentation focused on how different parts of the street were perceived sensorially, how particular car and bus engine noises became intensified under a bypass and the complexity of navigating crossings with several different traffic light systems. The third group focused on the passageways across and adjacent to John Dobson Street, while recognizing it as an interesting feature of the Street they felt had been abandoned and neglected.

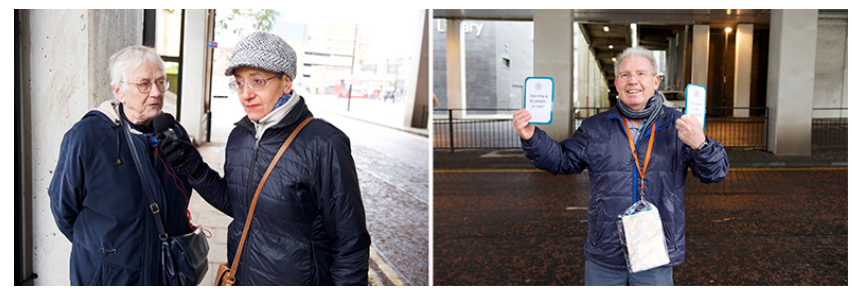

Figure 7. City Walks politics of planning group identifying areas of the street that they felt had been poorly designed for people and primarily serviced the needs of drivers.

\subsection{Organising media content}

After an hour the groups returned to the workshop space and marked out areas on individual maps where they had stopped, made comment and shared them with one another. As anticipated there were many overlaps where the groups had identified particular areas of John Dobson Street that could be improved by giving greater attention to people rather than traffic. Reflecting as a group, they also felt that they had each learned from one another. In particular as part of the group that focused on the politics of planning, one of them had significant local historical knowledge of the area and was able to contribute these perspectives to the discussion, which was greatly appreciated by other group members. Furthermore everybody in the groups had different perspectives and provided alternative and surprising suggestions that greatly enriched the experience. For instance there was a shared recognition that the 1970s development of John Dobson Street had indeed cut through the cultural heart of the city, splitting the City Gallery and Library into two buildings separated by the Street and many complicated crossings. The walkways and passages above and next to the Street, that had been built to accommodate such division felt neglected and yet these were an usual and significant feature of the cities history that had been forgotten and could be re-invigorated with graffiti or art. While many agreed with this, others felt that there were more important and practical problems to deal with.

Following the walk and as a final workshop activity we opened up a discussion about the different kinds of media that had been collected as part of the day. We suggested that if people were available the following week we could work with them to edit the audio, images and video into short snippets to either share with the transport planners or make available online via their own website. However individuals in the group expressed uncertainty and lack of confidence on whether their voices would be actually listened to by the city council and planners. began to be unsure and lost confidence in how they would be listened to. They reminded us that having never done anything like this before they needed technical assistance and reassurance that this was a valuable thing to do and spend time on.

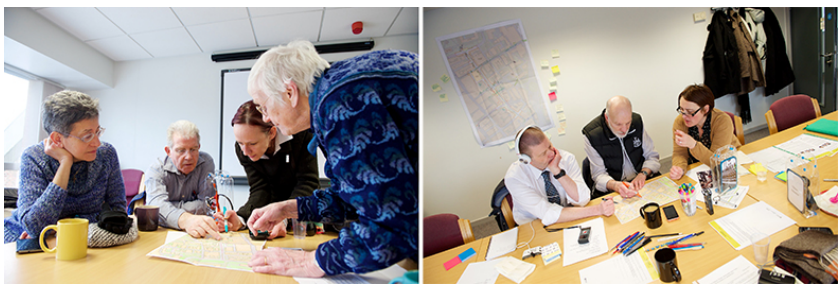

Figure 8. Evaluating routes on map and identifying important issues and comments the groups had collected on the walk.

\section{PRESENTING MEDIA}

Each of the groups met with the research team individually for an hour to edit down their comments and images into a short 2-3 minute video snippet, which provided further points for reflection and discussion on what data they had collected. Some of the group members mentioned that they felt self-conscious about their voices and the photographs being shown and preferred to not show themselves. Each of the groups was then invited to attend a consultation event that lasted throughout the week where the plans for John Dobson Street were being shown and engineers and planners were available to discuss their thoughts and ideas.

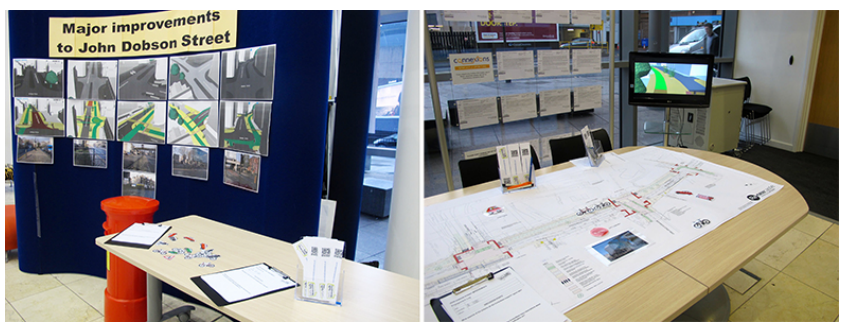

Figure 9. Consultation event at the City Library showing the technical plan for proposed changes to route and the 3D modeling of a visual fly-through to simulate what it would feel like for walkers and cyclists

Our initial plan was to show the engineers and planners the short videos that had been made with the Elders' Council to highlight some of the concerns they had raised. However the consultation process was highly structured and managed by community engagement officers acting as translators bridging the knowledge between the experts and the public. This was due to the fact that the plans were so technical and required significant amounts of interpretation about what it was the public was looking at. The community engagement officers had attempted to make the plans more legible by taking photographs of the existing parts of the road the plans referred to and placing the photographs next to specific parts of the map. Nonetheless without expert knowledge the plans required significant amounts of explanation and discussion to ensure they could be made sense of.

Our team of researchers visited the consultation event over 5 days that the exhibition was installed and covertly observed interactions between the planners and public for an hour each day. For some of the planners and engineers we had not met before we initiated discussion with them as interested members of the public 
before disclosing we were researchers. This was done in order to get a sense of how they made the plans accessible to us as members of the public, rather than just as researchers.

In addition to this we also spent time discussing with the community engagement officers some of the comments and feedback they were receiving and how they were collecting and analyzing feedback. Their role involved talking to members of the public, checking they understand the plans, and eliciting comments including positive and negative feedback. There was also an online feedback website which fed into this process. It was anticipated that all these comments would then be collated in terms of specific locations on the street and discussed in detail with the engineers who would then formulate ideas on how they could tackle issues or replicate what people felt was successful.

We also observed when members of the Elders' Council visited the consultation event how some of their interactions were fraught with miscommunication of different kinds of knowledge that were considered valid or invalid in the context of the specificity of the plans. One particular instance we noticed was when Elders' Council member Jim, who had significant experience of disability issues within the city, challenged the engineers suggesting a new position for an accessibility ramp that would make access for wheelchair users for easier and more direct. However the engineer pointed out how the ramp had to be positioned at a very particular angle, which was specified by disability legislation. Other suggestions based on the groups individual experiences however were received with much more recognition. Arthur, another Elders' Council member highlighted the removal of an island in a particularly tricky road crossing where cars came from several different directions. In describing his own experience and observing other peoples' challenges to cross the road in enough time, he told engineers it was useful to not only keep the current island that was in place, but also make it slightly larger. The engineer highlighted that they had not realized that this was such a problem for people and said that he felt it was worth noting this down to draw attention to when looking at the street as a whole.

What was clear from the consultation event and the ways in which the presentation of the plans was made available was that there was very little room for people to make alternative suggestions. Comments needed to be made and often negotiated either through the community engagement officers or with the engineers and planners through discussion. However the presentation of a very technical plan indicated that only slight tweaks and modifications to the existing proposal could be made and that this was at the final stages of technical approval.

\section{RE-CONFIGURING FUTURE COMMUNICATION}

In preparation for a follow-up workshop, between the consultation event and the second workshop in March, we met with the community engagement officers. This was important to understand how they had made sense of the data that had been collected throughout the consultation and if any changes had been made as a result of people's feedback. The meeting highlighted how several modifications had been made to benefit pedestrians, including responses to some of the comments made by members of the Elders' Council.

This discussion and all previous audio and video data collected was verbatim transcribed. We reviewed these through a close reading within the team and printed all associable photographs and field notes marking out particular moments of miscommunication and tension where different points of view were introduced and challenged by members of the group. We prepared audio-visual clips, quotes and full transcripts of the discussion with community engagement officers and of our previous workshop and the consultation for our follow-up workshop. This was to act as reminders of previous events so that members of the Elders' Council could also work with us as coresearchers and consolidate some of their reflections using material that had already been collected. This approach was especially chosen-to move the conversation on and rather than simply evaluate how the workshop and consultation could be improved, but also seek to come up with alternatives visions for how they could work in the future.

\subsection{Group reflections}

Two weeks later we came back together with the Elders' Council members to evaluate the different phases of the walking workshop. The focus was on considering these different phases and their value in effectively raising and communicating concerns with the City Council and to come up with alternative strategies. We began the workshop with an informal recollection of the walk itself, while people settled down with teas and coffees. This immediately highlighted a tension in how some of the group appreciated the open structure of the walks, while others wanted more direction in what specific data to collect in relation to the Street itself.

Jill: I remember going out and feeling like I didn't really have a clue what was going on, but I enjoyed this not really knowing what to expect and I had to think for myself.

Jim: Oh no I didn't like that I just wanted to get on with a task and collect data on specific problems. We focused more on accessibility issues, this was better.

We sensed that there was some prickliness between some of the group in highlighting some of these contrasting views, and so we explained that as researchers we felt these different points of view were valid in reflecting on their overall experiences since the purpose was not to limit perspectives, but to open up discussion.

We then began to outline how we wanted the group to take on the role of design researchers and asked what kinds of research they thought this would entail. This was first as a reflexive move to consider how members of the Elders' Council described what we did and how they then could begin to recognize themselves as researchers too. The group felt that what we did focused on finding out where and why particular things were happening and creating opportunities for improvement. We conducted experiments, collected quantitative and qualitative data, analysed our results and communicated this to make sure influential people took notice. Members considered parts of this process both fun and problematic-highlighting the difficulties associated with being noticed. it was to make sure people take notice.

Jill: Well when I say experiments, it's not like you put people in formaldyhyde and prod their brains or whatever (laughs). So I think we've been doing experiments with you and they're just a way of trying new things out aren't they? So we get to have a go. They've been a lot of fun.

Arthur: Yes really stimulating, I had a lot of fun, I think we all did.

Jim: The hard thing is getting people to take notice though - how do you make that happen? It sometimes feels you can have the best research in the world, but if nobody takes notice then it disappears. 
Collectively the group appeared to have a clear understanding of what was at stake in conducting and communicating research and some of the challenges this presented. With those particular understandings we then split the group into two, the first one to focus on the initial mapping exercise in the first workshop and the second on the walk itself. Finally the group came together to reflect on the consultation itself. Each activity posed the same questions:

Did the exercise support discussion and if so what did you discuss? What worked well about this activity? Was there anything you felt was missing? Opportunities for improvement?

\subsubsection{Community mapping}

The group reviewing the community mapping exercise began by looking through the available photographs, transcripts and quotes. Their first reactions were that they had talked a lot of 'rubbish' for much of the time, discussing a lot of things that felt unrelated to the main issues related to John Dobson Street. Some felt that it would've been better to have just got straight out and done the walk, but others who spent a little more time scanning the transcripts highlighted how they felt the exercise had been of value in other ways as an ice-breaker to get to know other members of the Elders' Council and to get to know their different travel routes, preferences and different levels of knowledge about the area.

Arthur pointed out how Mia in the transcripts had highlighted the difficulty in reading maps and the challenges this presented when initially looking at where and how they moved through the street. Danny agreed and described how difficult it was to read parts of the map as it was printed so lightly. At the same time it was difficult to connect what was on the map with what was in his head, what he could remember of particular places. Some of the discussion was therefore useful in collectively orienting individuals perceptions and recollections of place onto the map. This they felt was really useful in preparing people for the walk and for the consultation. This group felt that improvements could however be made through the use of video walk-throughs and Google Earth and much larger printed maps to walk along and annotate.

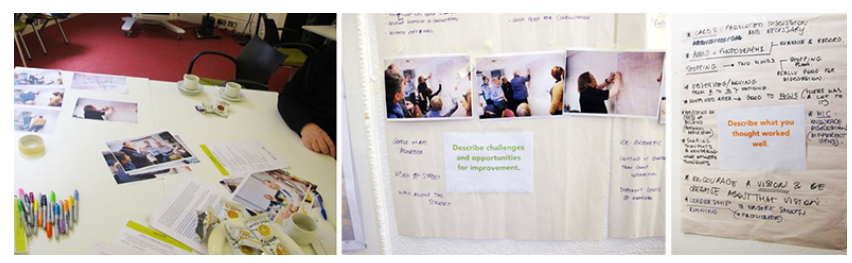

Figure 10. Evaluating different phases of the walking workshop and consultation events.

\subsubsection{City Walks}

The group evaluating City Walks began by reviewing the edited video, audio footage and photographs on a large screen on each of the three walks from the first workshop. After reviewing all the material and discussing this informally, they felt that the walks stimulated interesting discussion, but this was easier after rather than during the walks themselves, due to traffic noise and available space to gather together. They felt it was in fact easier to have more structured responses to place in situ, to have conversations within the built environment, but then to follow this up with discussion afterwards. The cards and the invitation to comment with the microphone were considered important for creating opportunities for stopping and evidencing responses, but this could often interrupt the flow of what often felt like a more natural conversation. Some however felt that the stopping and starting helped to keep things moving and helped them take notice of what they might otherwise completely miss. Listening to other people's points of view were, they felt an essential part of taking notice, encouraging learning about the different parts of the city they previously hadn't known about, leading to alternative creative visions of the spaces they were in. Others felt that the equipment however sometimes hindered discussion because there was a lot to think about with cameras and audio recorders, which sometimes dominated their attention. While some felt it would've been beneficial to see the proposed plans for the Street before the walk, others said they preferred not to and enabled them to have more of a vision for the Street and consider more of the aesthetic qualities.

\subsubsection{Consultation}

Each group then fed back their comments to each other before coming together to discuss how the workshop had helped the group communicate effectively with the planners. Overall the group was disappointed at how little impact and agency they felt they had in the context of the consultation. Many of the group felt the consultation was in fact just an exercise that the City Council had to go through. As a result they didn't feel they were being listened to and their ideas just weren't taken seriously. Many of them felt that the planners just wanted to talk at them, often what was said, they felt just went over their heads because it was too technical. While some said they felt that their comments were noted down, it was difficult to understand how this was logged systematically or what happened to their comments in relation to other comments that were made.

Two of the members who had never attended a consultation event such as this before however, said that the workshop, the walk beforehand and reviewing and editing their audio footage had given them the confidence to attend and felt they had something valuable to contribute. At first they were very self-conscious in looking at the plans and not really understanding what they were looking at, but they were approached by one of the engineers who was friendly and once he knew they had been on a walk with the Elders' Council seemed to take more notice of what was said. Having been on the walk previously and having spent some time discussing with others they felt that the workshop and the walk had really prepared them in being able to speak from their own experience with some authority and even encouraged them to visit the street again for another look.

While the group felt that overall they had had very little impact, everyone explained how they'd had a slightly different experience in communicating with the engineers based on their own expectations and personal approach. Members of the Elders' Council were therefore shocked to hear how some of their suggestions had indeed be taken forward, the small island to give people a place stop while crossing a busy junction and the bleakness of the underpass had been noted and a proposal for painting it to connect more with the colours of City Library had been accepted.

\subsection{Envisioning alternatives}

In the afternoon of the workshop we changed the focus from one of reflection to one of critical making and considering alternatives. We decided to do this by adapting an approach to making 'magic machines' [1][2][3][6], to engage the Elders' Council in developing alternative ideas. In these workshops participants are asked to imagine themselves into an alternative persona with which they develop by choosing a set of pre-defined characteristics. They then build a machine that helps them in their 
imagined day-to-day lives. Participants are only given basic craft materials (cardboard, paper, sellotape, string, straws) and the machine is constructed in a very limited timeframe, similar to cardboard mock-ups. Once completed, participants are asked to try out their machines in the world beyond the workshop and on returning describe the functionality and use of their machines. In performing the machines into being, this helps to provide a vocabulary, some narration and physical form to future desires that can often feel uncertain and vague. We felt this would be a generative way to give form to the Elders' Council ideas in a fun and lighthearted way, while at the same time taking seriously their commitments and concerns.

In order to adapt our activity to the context of the consultation, we set-up a fictional scenario 5 years in the future where the Elders' Council had won a prize from the UN for developing innovative approaches using technology to engage citizens in communicating with city planners. We presented this in the form of a printed newspaper and passed this round (Fig. 11). We introduced the activity while people sat down around the table with us and described it as follows: We are in the year 2020 and over the past 5 years you have been working with the Elders' Council to develop City Walks as a successful form of communication with city planners. As researchers we are now working for the UN and are going to present you with a prize for the innovative approaches and technology you have created to enable greater communication between citizens and planners. You have an hour to make your ideas using the available craft materials and you will return to this table to present them to us.

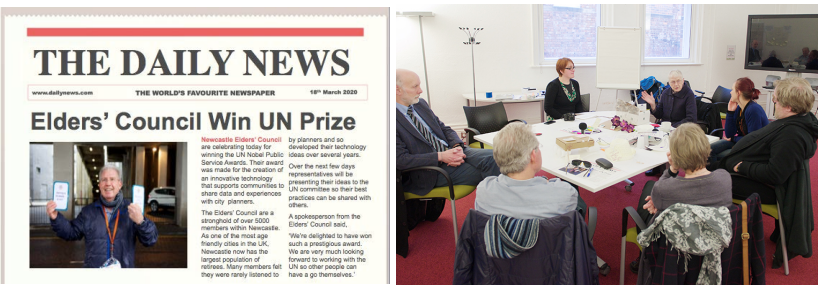

Figure 11. Fictional scenario as presented in a newspaper whereby the Elders' Council have won a prize on the development of alternative technology to support citizens communicating more effectively with city planners.

Everyone began to laugh at the printed newspaper article and some became excited clapping their hands at the possibilities of what they could do. Some of the group however expressed some reticence at being able to make anything at all to which we reassured them that the focus was on making stories around what was made, not worrying about how well they could make things. On approaching the table with materials Val, Arthur, Mia and Jill began picking things up, showing them to one another and placing them on themselves and each other while laughing at what they could be. Danny and Jim were however more self-conscious about what they should work on and preferred to initially watch the rest of the group, picking up materials as they walked around the edges of the table to get some inspiration.

As people settled into making either in teams or individually, and as shapes, cables, and antennae began to emerge from cardboard, boxes, hats and glasses, we began to gently ask the groups questions about what it was they were making and what the objects could do. We challenged the group to describe why they felt what they made could improve the current situation, who would take responsibility for maintenance and where this equipment would be stored and charged, as they added final touches or additional functionalities.
Jill, Mia and Arthur, began to work together on ideas that started from existing technology that they were familiar with and had recently read about or seen on the news. They imagined a collection of connected technologies for the city; 'The Hackers Hat', 'Advanced Google Live Feed' and 'The People's Printer' (Fig 12). These ideas all came together around the idea of an inner city carnival that would encourage people to collect data about older people's use of the city through celebration. The Hacker's Hat would push notifications to people's mobile devices in Newcastle to communicate the latest news on the 'carnival'. The hats would be are hackable by anyone with basic knowledge of technology and could be purchased for a reasonable price. Hacker Hat selling would become a social enterprise and the money raised contributing to further expansion of the carnival scheme. Advanced Google Live Feed would accompany the carnival through an enhanced version of Google glasses analyzing data and feeding this back to local councilors to show them exactly how the city is used in real time. The People's Printer would use data from the Google live feed to automatically generate alternative visions for the city. It would print these ideas out in miniature so people could collectively bring them together and discuss potential plans for change. The printer is not officially owned by anyone and moves around on wheels to communities as and when it is needed.

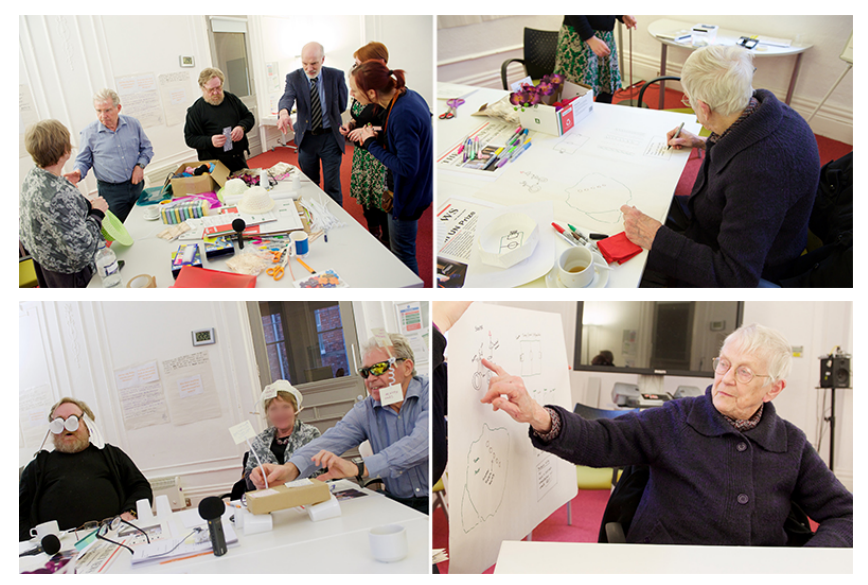

Figure 12. Making cardboard machines and sketches. Presenting ideas for fantasy technologies to improve communication between city planners and older people.

Val presented the 'Technology Resistant Nonagenarian Scooter Movement'. This included purpose built scooters, scooter lanes and charging points around the city. The scooters would be designed for social movements and would include holders for a map, umbrella and placards, also a wool dispenser to mark out particularly good and bad scooter routes in the city. The nonagenarians (people over 90) would mark out the most inaccessible buildings, the most comfortable seats and the best public toilets through mass protest and organized scooter marches and would use the local football ground to practice and train. Danny, helped by Jim created 'Eyes and Ears'; an augmented glasses and ear attachment to help planners listen more effectively and learn from people's everyday experiences. The system could be supplied in each of the planning officers drawers so that when they walked down the street they could really listen and see some of the challenges people were having.

The technologies and scenarios created were fantastical and were very much situated in the context of the city, future desires and existing knowledge of technologies available. Most importantly the technologies involved supporting the Elders' Council in 
organising events and co-ordinating action. Media making and presentation was configured into something much more celebratory and carnivalesque rather than just technically information oriented.

\section{DISCUSSION}

Media architecture is a relatively new field of study, yet it is increasingly becoming significant in the context of urban development and growing urban populations, many of whom are living longer. This presents both opportunities and challenges for engagement with change-making processes and media content generation and sharing. Furthermore as many governments engage in smart city agendas, it is also important for communities and groups to have a say on what the future of cities might look and feel like [15] [22]. The collection and reflection on big data analytics available from sensors and mobile phones is increasingly an important part of this discussion. However it is also important to consider opportunities for place-based rich media content that enables wider reflection, discussion and contention at scale. This may enable greater layering of different processes, such as sensemaking, awareness raising and storytelling around place, but also make issues palpable and sharable across differences [30].

While the primary focus of our research was not to develop media content in relation to architecture, our exploratory study suggests potential future value for considering media architecture in the context of public participation and deliberation around space and place for older people. Our intention has been to open up a discussion on how such processes and media produced may take advantage of media architecture as potential interventions in places where change is about to take place. As yet we have not developed such interventions, which understandably limits the impact of our contribution. However we are increasingly presented with opportunities to do so in the context of the creation of media facades and architectural urban screens. We offer tentative directions for further research in making public processes of experimentation and translation through celebrating alternative perspectives of older adults knowledge and experiences of urban life.

\subsection{Experimentation}

Research in media architecture has shown the advantages of open and creative forms of participatory engagement with people in the urban environment [4][7][26][30]. We developed our approach to working with the Elders' Council explicitly as creative experimentation in order to allow room for particular issues and concerns to be expressed. While we were initially familiar with the fact that the group felt that they were not being listened to by the council, encouraging audio-visual media creation from walking and then physically making alternative technologies as a form of exploration moved the conversation forward in ways that the group hadn't considered or felt they could achieve before. While more aesthetic and cultural interests were raised in earlier workshops, the session formats and opportunities to engage with multiple points of view brought these interests to the fore and made them public and actionable in the context of the planning consultation. While some were disappointed that their issues had not been addressed more directly during the consultation, others felt the workshops had given them confidence to talk about their experiences and share their knowledge. The value of openness, in this sense entails trying out new ways of doing to see what would happen in the context of framing the sessions as experimentation, that we attempted to engender in the workshops was continued through into the consultation.

\subsection{Translation}

A further value to the experimental approach we took to the sessions was that it allowed for a network of significant actors to emerge from the process as described by [17]. In this sense the process was valuable in making palpable the roles and responsibilities of those involved in making decisions about what should happen next, and highlighted many different physical and digital media tools used to communicate ideas and elicit feedback and share visions. While we had initially focused on the Elders' Council and their communication with the transport and planning department, what became clear was the importance of community engagement officers to provide interpretation, information and a more human perspective to the more official and technical expertise required to make things happen on the ground. Community engagement officers were very accomplished at acting as bridges working between different organisations and vocabularies to ensure discussions were meaningful and relevant to different parties also using a range of media to do this informative way. Community engagement officers not only kept in touch with us and the Elders' Council as and when new developments were taking place, but were also interested in the technologies we were using and our experiences of the walk and the consultation.

Further to this it was also important to recognize the interpersonal translation required in order to make the audio-visual media collected from the walks, relevant within the context of the consultation. While we could have shown short video and audio clips, these would've also required some interpretation and discussion with the planners and engineers to make the communication meaningful, but in many respects this appeared unnecessary and more direct interaction was preferred so questions could be asked and details of the plan explained. This is not to say that the media collection and presentation had no value because it was not directly shared. Rather the audio-visual media collected and then edited helped individuals rehearse their ideas and for some built their confidence to discuss these with each other and then at the consultation event.

\subsection{Celebration}

The workshops and the consultation event did not however support a more public sharing of the media collected by the group. The experimental nature of the sessions sometimes meant that individuals talked about feeling self-conscious about taking creative risks and sharing something they had made with a much wider audience. Yet, in the future envisioning session where the group re-imagined and re-configured future communication with city planners, their visions were very much oriented towards large-scale participation and public sharing in celebratory and carnivalesque ways. We see the role of media architecture in the context of urban planning in having the potential for experiences, information and plans to be made available through celebrating the built environment to make issues, not necessarily visible, but at least namable and palpable so they can be recognized and discussed more widely.

\section{CONCLUSION}

As urban populations are expanding and ageing alternative approaches are needed to understand and engage with the concerns of older adults. We have argued that media architecture could play a more significant role in helping to translate and make palpable diverse experiences and histories in more creative, responsive and situated ways. These are aspects of planning that are often invisible to citizens, but could in fact help to foreground 
contentions and matters of concern raised by groups that highlight the aesthetics of place, enchanting and more playful experiences. While an emphasis on technology designed for ageing can often emphasise accessibility issues, taking an experimental approach informed by mobilities research helped to re-configure alternative visions of what participation in city planning using digital media might look and feel like in the future. By foregrounding our teams interests in poetics, politics and perceptions of place, we devised a series of workshops using technologies that were familiar enough to support the documentation and sharing of multiple perspectives by a group of older adults. While this sometimes led to managing conflictual points of view, and the necessity of translation, these were valued and helped to structure greater confidence and agency in reflecting and commenting on future urban plans.

\section{ACKNOWLEDGMENTS}

Thank you to members of the Elders' Council whose passion and enthusiasm made the research possible. This research was funded by RCUK, EPSRC Grant No: EP/K037366/1. Data supporting this publication is openly available under an 'Open Data Commons Open Database License'. Additional metadata are available at: 10.17634/123905-1. Please contact Newcastle Research Data Service at rdm@ncl.ac.uk for access instructions.

\section{REFERENCES}

[1] Andersen K. 2013. Making Magic Machines, 10th European Academy of Design Conference - Crafting the Future.

[2] Andersen, K. 2014. The Deliberate Cargocult. In Proc. DIS'14 ACM, 627-636.

[3] Andersen, K. \& Wilde, D. 2012. Circles and Props: Making Unknown Technology, Interactions, (May 2012) 19,3, ACM, 60-65

[4] Andersen, C.U. \& Pold, S.B. 2012. Occupation of the Open City. In Proc. MAB'12, ACM New York, 1-4.

[5] Balaam, M., Comber, R., Jenkins, E., Sutton, S. \& Garbett, A. 2015. FeedFinder: A Location-Mapping Mobile Application for Breastfeeding Women. In Proc. CHI'15, ACM, 1709-1718.

[6] Blythe, M., Andersen, K., Clarke, R., Wright, P. 2016. AntiSolutionist Strategies: Seriously Silly Design Fiction. In Proc. CHI'16, ACM (In press).

[7] Caldwell, G.A. \& Foth, M. 2014. DIY Media Architecture: Open and Participatory Approaches to Community Engagement. In Proc. MAB'14, ACM, 1-10.

[8] Colangelo, D. 2014. The Empire State Building and the Roles of Low-Resolution Media Facades in a Data Society. In Proc. MAB'14, ACM, 11-20.

[9] Cresswell, T. 2010. Towards a Politics of Mobility. Environment and Planning D: Society \& Space (28) 17-31.

[10] Cresswell, T. 2011. Mobilities II. Still. Progress in Human Geography. 1-9.

[11] Crivellaro, C., Comber, R., Dade-Robertson, M., Bowen, S., Wright, P. \& Olivier, P. 2015. Contesting the City: Enacting the Political through Digitally Supported Urban Walks. In Proc. CHI'15, ACM, 2853-2862.

[12] Dade-Robertson, M., Taylor, N., Marshall, J. \& Olivier, P. 2012. The Political Sensorium. In Proc. MAB'12, ACM, 4750 .
[13] Di Mascio, D. \& Maver, T. 2014, Investigating a narrative architecture - Mackintosh's Glasgow School of Art, Thompson, Emine Mine (ed.), Fusion - Proceedings of the 32nd eCAADe Conference - Volume 1, pp. 653-663.

[14] Elliot, A. \& Urry, J. 2010. Mobile Lives. London, Taylor \& Francis.

[15] Greenfield A. 2013. Against the Smart City: The City is Here for You to Use. Kindle edition.

[16] Ingold, T. 2010. Lines: A Brief History. London, Routledge.

[17] Korsgaard, H. 2014. City Bug Report: Urban prototyping as participatory process and practice. In Proc. MAB'14, ACM, 21-29.

[18] Kukka, H., Foth, M. \& Dey, A. K. Transdisciplinary approaches to urban computing. Int. J. Human-Computer Studies 81 (2015) 1-3.

[19] Kukka, H., Luusua, A., Ylipulli, J., Suopajarvi, T., Kostakos, V., Ojala, T. 2014. From cyberpunk to calm urban computing: Exploring the role of technology in the future cityscape. Journal of Technological Forecasting and Social Change. Vol 84, May 2014, 29-42.

[20] LeDantec, C. A., Asad, M., Misra, A., Watkins, K.E. Planning with crowdsourced data: Rhetoric and representation in transportation planning. In Proc. CSCW'15, ACM, 1717-1727.

[21] Light, A., Leong, T.W. and Robertson, T. 2015. Ageing Well with CSCW, in Proc. ECSCW 2015, London: Springer.

[22] Mulgan, G. 2014. Social and technical innovation, future cities and the digital economy. Presentation at Digital Economy Conference, Imperial College London, Dec 2014.

[23] Ormerod, M., Newton, R., Phillips, J., Musselwhite, C., McGee, S. \& Russell, R. 2015. How can transport provision and associated built environment infrastructure be enhanced and developed to support the mobility needs of individuals as they age? London: Government Office for Science.

[24] Perkins, C. 2007. Community Mapping. The Cartographic Journal. 44 (2) pp 127-137.

[25] Taylor, A.S., Lindley, S., Regan, T, Sweeney, D., Vlackokyriakos, V., Garinger, L \& Lingel, J. Data-in-Place: Thinking through the Relations Between Data and Community. In Proc. CHI'15, ACM, 2863-2872.

[26] Toft, T.S. 2014. Situations of Presence: Reclaiming Public Space in the Urban Digital Gallery. In Proc. MAB'14, ACM New York, 79-84.

[27] Urbanowicz, K. \& Nyka, L. 2012. Media architectureparticipation through the senses. In Proc. MAB'12, ACM New York, 51-54.

[28] Vines J., Pritchard, G., Wright, P., Olivier, P., Brittain, K. An Age Old Problem: examining the Discourses of Ageing in HCI and Strategies for Future Research. TOCHI. Volume 22 Issue 1, Mar 2015

[29] Virtual Newcastle Gateshead http://www.virtualng.northumbria.ac.uk

[30] Willis, K., Corino, G. \& Martin, K. Developing a Neighbourhood Locative Media Toolkit. In Proc. MAB'12, ACM New York, 75-78. 